\title{
An accurate inter-turn short circuit faults model dedicated to
} induction motors

\author{
Fatima Babaa', Ouafae Bennis ${ }^{2}$ \\ ${ }^{1}$ Electrical Laboratory of Constantine "LEC", University of Constantine 1, Algeria \\ ${ }^{2}$ Prisme Laboratory, University of Orleans, France
}

\begin{abstract}
Article Info
Article history:

ABSTRACT

Received Dec 2, 2019

Revised Jun 10, 2020

Accepted Jul 30, 2020

eywords:

Indicator fault

Induction machines

Inter-turn short-circuit fault

New model

Safety, disponibility and continuity of industrial systems are major issue in maintenance. In the last decades, these points are the important axes in the field of research. In fact, in many industrial processes research has picked up a fervent place and a particular importance in the area of fault diagnosis of electrical machines, in fact, a fault prognosis has become almost indispensable. The need of a mathematical model of three-phase induction machine, suitable for the simulation of machines behaviour under fault conditions, has received considerable attention. The paper presents a new practical and more precise model for induction motors after introducing inter turn short circuits faults. The proposed model is based on coupled magnetic circuit theory, capable to take into account any electrical asymmetry conditions. To verify the exactitude and the effectiveness of the model, simulation results for induction machine under interturn short circuit fault are presented. In spite of its simplicity, the proposed model is able to provide useful indications for diagnostic purposes. Experimental study is presented at the end of the paper to show that the proposed model predicts the induction machine behavior with a good accuracy.
\end{abstract}

This is an open access article under the CC BY-SA license.

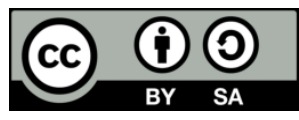

Corresponding Author:

Fatima Babaa,

Department of Electrical Engineering,

Electrical Laboratory of Constantine "LEC",

University of Constantine 1, 25000 Constantine, Algeria.

Email: babaa.fatima@yahoo.fr

\section{INTRODUCTION}

Many of the works presented in literature have shown that a most of failures in induction machines are caused by stator winding faults $[1,2]$. For example, the turn-to-turn short circuit faults, in stator windings, represent the most of the existing faults in induction machines [3]. In most cases inter-turn short circuits fault is caused by thermal, thermomechanical, vibrational and environmental factors occurs during the operational phase [4-6]. It is also well known that cage induction motor is the most electromechanical form used in many areas such as electromechanical drive in industrial, commercial and domestic applications. Diagnosing failures of industrial systems, if it can be possible to identify in a timely manner, represents one of the means of increasing gain points of productivity. In the literature, several diagnostic methods are proposed to detect stator and rotor faults [7-13] such as through control techniques [14-16]. Any reliable proposed method of diagnosis should be based on the study of the electromagnetic and mechanical behaviour of the motor in both healthy and under fault conditions [17-19].

For a good and effective understanding diagnosis, the challenge is to have an accurate and appropriate analytical model which represents the real machine in healthy or faulty conditions like for motorpump system [20]. A large number of mathematical models of three-phase induction motors have been 
seriously studied in the past decades [21-23]. Induction motor models are developed based on suitable mathematical descriptions, which have relevant dynamic description of the processes associated with induction motor operation in healthy and faulty conditions. It is agreed that the difficulty in obtaining an accurate model is a tradeoff between complex, effectiveness and reliable characteristic.

Even if the difficulty of controlling the factors influencing the operation of the machine as well as all the non-idealities exists, a model, as accurate as possible, must be available to extract the fault indicators [24-28]. So, there is a real need to develop an accurate model that can take into account the impact of default and predict it before it grows and damages the machine completely. The developed model relies on coupled magnetic circuit theory and allows detection of electrical faults, like shorted faults in stator windings. In this paper, a judicious, precise and effective mathematical model that could be used to monitor induction machine in healthy and faulty conditions is proposed. To demonstrate the effectiveness of the model, simulation and experimental results are shown at the end of this paper

\section{MOTOR MODEL IN ABC MODEL COORDINATES INCLUDING INTER-TURN SHORT CIRCUITS FAULT}

2.1. Healthy machine

To modeling three-phase induction motor, it is necessary to put some hypotheses to achieve a simple and useful model:

- There is no magnetic saturation during operation.

- Magneto-motive force ( $\mathrm{mmf}$ ) and flux are considered sinusoidally distributed.

- Harmonics in this model are neglected.

- Magnetism of iron is considered as unlimited and the air gap is negligible and smooth.

Currents, voltages and flux linkage equations of the mathematical model are generally carried out in the stationary reference systems $\mathrm{a}, \mathrm{b}$ and $\mathrm{c}$.

$$
\left\{\begin{array}{l}
{\left[V_{s}\right]=\left[R_{s}\right] \cdot\left[I_{s}\right]+\frac{d\left[\Phi_{s}\right]}{d t}} \\
{\left[V_{r}\right]=\left[R_{r}\right] \cdot\left[I_{r}\right]+\frac{d\left[\Phi_{r}\right]}{d t}}
\end{array}\right.
$$

where:

$$
\left\{\begin{array}{l}
{\left[\Phi_{s}\right]=\left[L_{s s}\right] \cdot\left[I_{s}\right]+\left[M_{s r}\right] \cdot\left[I_{r}\right]} \\
{\left[\Phi_{r}\right]=\left[M_{s r}\right]^{t}\left[I_{s}\right]+\left[L_{r r}\right] \cdot\left[I_{r}\right]}
\end{array}\right.
$$

with,

$$
\left[I_{s}\right]=\left[\begin{array}{lll}
i_{s a} & \mathrm{i}_{\mathrm{sb}} & \mathrm{i}_{\mathrm{sc}}
\end{array}\right]^{t}\left[I_{r}\right]=\left[\begin{array}{lll}
i_{r a} & i_{r b} & i_{r c}
\end{array}\right]^{t}\left[V_{s}\right]=\left[\begin{array}{lll}
v_{s a} & \mathrm{v}_{\mathrm{sb}} & \mathrm{v}_{\mathrm{sc}}
\end{array}\right]^{t}
$$

$\left[R_{s}\right]=R_{s} \cdot 1_{3 \times 3}$; is the stator matrix resistance, and the stator inductance matrix is given by:

$$
\left[L_{s s}\right]=\left(\begin{array}{ccc}
L_{s a a} & M_{s a b} & M_{s a c} \\
M_{s b a} & L_{s b b} & M_{s b c} \\
M_{s c a} & M_{s c b} & L_{s c c}
\end{array}\right)\left[L_{r r}\right]=\left(\begin{array}{ccc}
L_{r a a} & M_{r a b} & M_{r a c} \\
M_{r b a} & L_{r b b} & M_{r b c} \\
M_{r c a} & M_{r c b} & L_{r c c}
\end{array}\right)
$$

where

$L_{s a a}=L_{s b b}=L_{s c c}=l s ;$ the stator self inductance,

$M_{s a b}=M_{s a c}=M_{s b c}=M_{b a}=M_{c a}=M_{c b}=M_{s}$; the stator phase mutual inductance.

$L_{r a a}=L_{r b b}=L_{r c c}=l r ;$ the stator self inductance,

$M_{r a b}=M_{r a c}=M_{r b c}=M_{r a}=M_{r a}=M_{r b}=M_{r}$; the rotor phase mutual inductance. 
$\left[M_{s r}\right]$ the mutual inductance matrix between the stator and rotor, which is function of $\theta$, the spatial position of the rotor.

$$
\left[M_{s r}\right]=M_{s r}\left[\begin{array}{ccc}
\cos (\theta) & \cos \left(\theta+\frac{2 \pi}{3}\right) & \cos \left(\theta-\frac{2 \pi}{3}\right) \\
\cos \left(\theta-\frac{2 \pi}{3}\right) & \cos (\theta) & \cos \left(\theta+\frac{2 \pi}{3}\right) \\
\cos \left(\theta+\frac{2 \pi}{3}\right) & \cos \left(\theta-\frac{2 \pi}{3}\right) & \cos (\theta)
\end{array}\right]
$$

\subsection{Turn-to-turn shorted circuit model}

Turn-to-turn short circuit fault causes one or more additional windings in faulty phase and reduce the effective winding as shown in Figure 1.
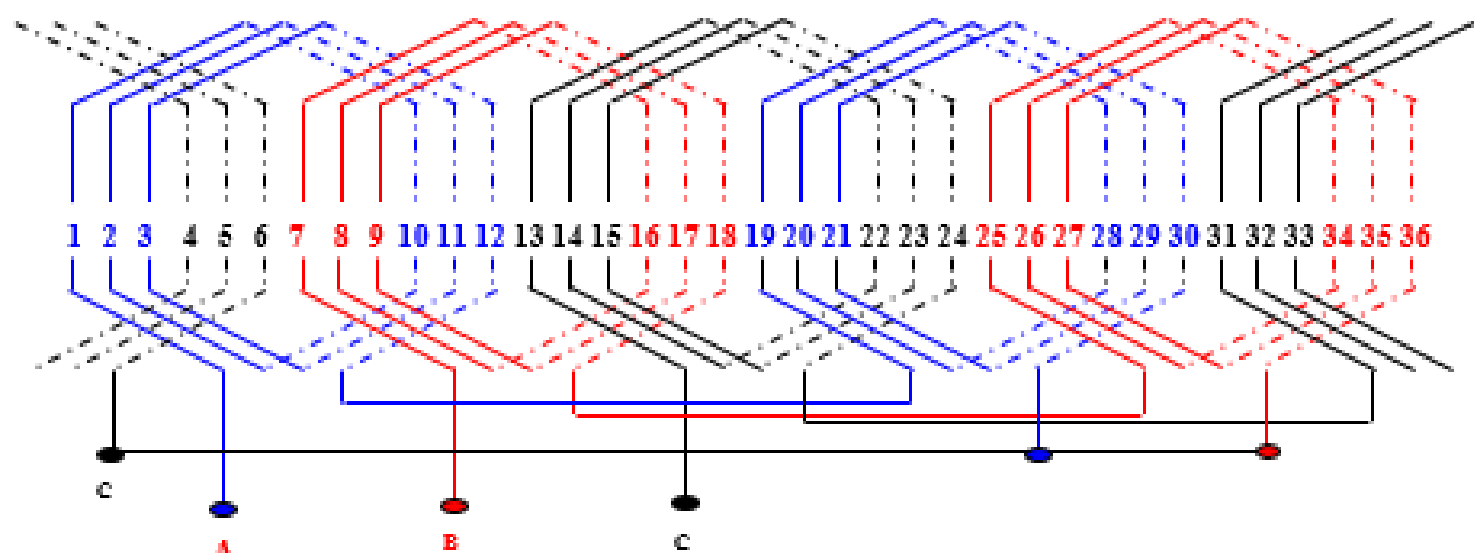

Figure 1. Diagram of stator phases windings including inter-turn short circuits fault in phase A

To consider a short-circuit fault, it is required to define two parameters indispensable for the understanding of the model [5-7]. $\eta_{c c}$ is a short-circuited turns parameter and it defined as:

$$
\eta_{c c}=\frac{\text { Number of int er }- \text { turns short }- \text { circuit windings }}{\text { Total number of int er-turns in one phase }}
$$

Turn faults equation can be expressed as:

$$
0=R_{c c} i_{c c}+\frac{d}{d t} \phi_{c c}
$$

where $\phi_{c c}=\left[M_{c c s}\right]\left[i_{s}\right]+\left[M_{c c r}\right]\left[i_{r}\right]+L_{c c} i_{c c}$

$$
\left[M_{s c c}\right]=\eta_{c c} l_{s p}\left[\begin{array}{l}
\cos \left(\theta_{c c}\right) \\
\cos \left(\theta_{c c}-\frac{2 \pi}{3}\right) \\
\cos \left(\theta_{c c}+\frac{2 \pi}{3}\right)
\end{array}\right]\left[M_{r c c}\right]=\eta_{c c} l_{s p}\left[\begin{array}{l}
\cos \left(\theta_{c c}-\theta\right) \\
\cos \left(\theta_{c c}-\theta-\frac{2 \pi}{3}\right) \\
\cos \left(\theta_{c c}-\theta+\frac{2 \pi}{3}\right)
\end{array}\right]
$$

When the short circuit occurs in the phase $s_{a}, \theta_{c c}$ can be given as $\theta_{c c}=0$. 


\section{INTER-TURN SHORT CIRCUITS FAULTS MODEL IN $(\alpha, \beta)$ COORDINATES}

Three-phase quantities (voltages, currents and flux linkage) are converted in $(\alpha, \beta)$ coordinates to resolve differential equations with variable coefficients. The 2-phase stationary $(\alpha, \beta)$ is used to reduce the number of equations and to eliminate the interdependence found in the mutual inductances matrix between stator and rotor. These fictive coils are electrically and magnetically equivalent to the real coil.

Clark transformation equation is of the form:

$$
\left[X_{o \alpha \beta}\right]=\left[\begin{array}{lll}
X_{r o} & X_{r \alpha} & X_{r \beta}
\end{array}\right]^{t}=[C]^{-1} \cdot\left[X_{3}\right]
$$

with:

$$
[C]=\sqrt{\frac{2}{3}} \cdot\left(\begin{array}{ccc}
\frac{1}{\sqrt{2}} & 1 & 0 \\
\frac{1}{\sqrt{2}} & -1 / 2 & \sqrt{3} / 2 \\
\frac{1}{\sqrt{2}} & -1 / 2 & -\sqrt{3} / 2
\end{array}\right)
$$

After applying the transformation, the model becomes:

$$
\left\{\begin{array}{l}
{\left[\begin{array}{l}
V_{s \alpha} \\
V_{s \beta}
\end{array}\right]=0=\left(\begin{array}{cc}
R_{s} & 0 \\
0 & R_{s}
\end{array}\right)\left(\begin{array}{l}
i_{s \alpha} \\
i_{s \beta}
\end{array}\right)+\frac{d}{d t}\left[\begin{array}{l}
\phi_{s \alpha} \\
\phi_{s \beta}
\end{array}\right]} \\
{\left[\begin{array}{l}
V_{r \alpha} \\
V_{r \beta}
\end{array}\right]=0=\left(\begin{array}{cc}
R_{r} & 0 \\
0 & R_{r}
\end{array}\right)\left(\begin{array}{l}
i_{r \alpha} \\
i_{r \beta}
\end{array}\right)+\frac{d}{d t}\left[\begin{array}{l}
\phi_{r \alpha} \\
\phi_{r \beta}
\end{array}\right]+\frac{d \theta_{r}}{d t}\left(\begin{array}{cc}
0 & -1 \\
1 & 0
\end{array}\right)\left[\begin{array}{l}
\phi_{r \alpha} \\
\phi_{r \beta}
\end{array}\right]}
\end{array}\right.
$$

Equation of flux linkage can be expressed as:

$$
\left\{\begin{array}{l}
{\left[\begin{array}{l}
\phi_{s \alpha} \\
\phi_{s \beta}
\end{array}\right]=\left(\begin{array}{ll}
L_{s} & 0 \\
0 & L_{s}
\end{array}\right)\left(\begin{array}{l}
i_{s \alpha} \\
i_{s \beta}
\end{array}\right)+\left(\begin{array}{cc}
M & 0 \\
0 & M
\end{array}\right)\left(\begin{array}{l}
i_{r \alpha} \\
i_{r \beta}
\end{array}\right)} \\
{\left[\begin{array}{l}
\phi_{r \alpha} \\
\phi_{r \beta}
\end{array}\right]=\left(\begin{array}{cc}
L_{r} & 0 \\
0 & L_{r}
\end{array}\right)\left(\begin{array}{l}
i_{r \alpha} \\
i_{r \beta}
\end{array}\right)+\left(\begin{array}{cc}
M & 0 \\
0 & M
\end{array}\right)\left(\begin{array}{l}
i_{s \alpha} \\
i_{s \beta}
\end{array}\right)}
\end{array}\right.
$$

with: $\quad M=\frac{3}{2} m_{s r}, L_{r}=l_{r}-m_{r}, L_{s}=l_{s}-m_{s}$

$$
\left[\phi_{c c}\right]=\eta_{c c}^{2} l_{s} i_{c c}+\eta_{c c} \sqrt{\frac{2}{3}}\left(\begin{array}{ll}
L_{s} & 0
\end{array}\right)\left(\begin{array}{l}
i_{s \alpha} \\
i_{s \beta}
\end{array}\right)+\eta_{c c} \sqrt{\frac{2}{3}} M(1 \quad 0)\left(\begin{array}{l}
i_{r \alpha} \\
i_{r \beta}
\end{array}\right)
$$
as follows:

After transformation into $(\alpha, \beta)$ coordinates, the mathematical model of the induction motor is given

$$
\begin{aligned}
& V_{s \alpha}=R_{s} i_{s \alpha}+\frac{d}{d t}\left(L_{s} i_{s \alpha}+\eta_{c c} L_{s} \sqrt{\frac{2}{3}} i_{c c}+M i_{r \alpha}\right) \\
& V_{s \beta}=R_{s} i_{s \beta}+\frac{d}{d t}\left(L_{s} i_{s \beta}+M i_{r \beta}\right) \\
& V_{r \alpha}=0=R_{r} i_{r \alpha}+\frac{d}{d t}\left(M i_{s \alpha}+\eta_{c c} M \sqrt{\frac{2}{3}} i_{c c}+L_{r} i_{r \alpha}\right)+\frac{d \theta}{d t}\left(M i_{s \beta}+L_{r} i_{r \beta}\right)
\end{aligned}
$$




$$
\begin{aligned}
& V_{r \beta}=0=R_{r} i_{r \beta}+\frac{d}{d t}\left(M i_{s \beta}+L_{r} i_{r \beta}\right)-\frac{d \theta}{d t}\left(M i_{s \alpha}+\eta_{c c} M \sqrt{\frac{2}{3}} i_{c c}+L_{r} i_{r \alpha}\right) \\
& V_{c c}=0=\eta_{c c} R_{s} i_{c c}+\frac{d}{d t}\left(\eta_{c c} L_{s} \sqrt{\frac{2}{3}} i_{s \alpha}+\eta_{c c}^{2} l_{s} i_{c c}+\eta_{c c} M \sqrt{\frac{2}{3}} i_{r \alpha}\right)
\end{aligned}
$$

From previous equations, if we precede a good rearranging the machine equations can be expressed as:

$$
V_{s \alpha}=R_{s}\left(i_{s \alpha}+\eta_{c c} \sqrt{\frac{2}{3}} i_{c c}\right)+\frac{d}{d t}\left\{\begin{array}{l}
L_{s}\left(1+\eta_{c c} \frac{2}{3}\right)\left(i_{s \alpha}+\eta_{c c} \sqrt{\frac{2}{3}} i_{c c}\right)+ \\
+M\left(1+\eta_{c c} \frac{2}{3}\right) i_{r \alpha}
\end{array}\right\}
$$

To facilitate the comprehension of the equation system weput:

$$
i_{s \alpha}+\eta_{c c} \sqrt{\frac{2}{3}} i_{c c}=i_{s \alpha}
$$

The new equation system becomes:

$$
\left\{\begin{array}{l}
\frac{V_{s \alpha}}{\left(1+\eta_{c c} \frac{2}{3}\right)}=\frac{R_{s}}{\left(1+\eta_{c c} \frac{2}{3}\right)} i_{s \alpha}{ }^{\prime}+\frac{d}{d t}\left\{L_{s} i_{s \alpha}{ }^{\prime}+M i_{r \alpha}\right\} \\
V_{s \beta}=R_{s} i_{s \beta}+\frac{d}{d t}\left(L_{s} i_{s \beta}+M i_{r \beta}\right) \\
V_{r \alpha}=0=R_{r} i_{r \alpha}+\frac{d}{d t}\left(M i_{s \alpha}{ }^{\prime}+L_{r} i_{r \alpha}\right)+\frac{d \theta}{d t}\left(M i_{s \beta}+L_{r} i_{r \beta}\right) \\
V_{r \beta}=0=R_{r} i_{r \beta}+\frac{d}{d t}\left(M i_{s \beta}+L_{r} i_{r \beta}\right)-\frac{d \theta}{d t}\left(M i_{s \alpha}{ }^{\prime}+L_{r} i_{r \alpha}\right)
\end{array}\right.
$$

The last system of equations is complemented with the electromagnetic torque $\Gamma_{e}$ that is obtained from the magnetic coenergy $W_{c o}$.

$$
\begin{aligned}
& \Gamma_{e}=\left[i_{s a b c c c}\right]^{t} \frac{\partial}{\partial \theta}\left[M_{s r}\right]\left[i_{r a b c}\right] \\
& \Gamma_{e}=\sqrt{\frac{3}{2}} M_{s r}\left(-\left(\frac{1}{3} i_{s \alpha}+\eta_{c c} i_{c c}\right) \times i_{r \beta}+i_{s \beta} \times i_{r \alpha}\right)
\end{aligned}
$$

\section{SIMULATION RESULTS}

To extract in a precise way the information related to the stator defaults and to validate the mathematical model, we used the spectra of stator current to make possible accurately the visualization of the indices for detection and identification the shorted faults. The differential equations obtained are treated in the fourth order Runge-Kutta method. To validate the mathematical model, Figures 2 and 3 show detailed waveforms of currents and motor torque respectively, with applied $20 \%$ of inter turn short circuits faults appearing at time $1.5 \mathrm{~s}$ respectively. We remark that important short circuit current appears. In the corresponding FFT spectrum of the current as shown in Figure 4 it can be possible to identify precise frequencies correlated to early fault. We clearly observe that amplitude of some negative and positive frequencies is responsive of the fault. Theses frequencies increase with the augmentation of interturn short circuit. We remark the augmentation of $-f$ frequency. This inverse sequence is reflected on the rotor side and produces new components in the stator currents at frequencies $\pm 3 f$. These frequencies which appear after application of the interturn short circuit fault are very quoted in the literature. This result shows the correctness of our model. 


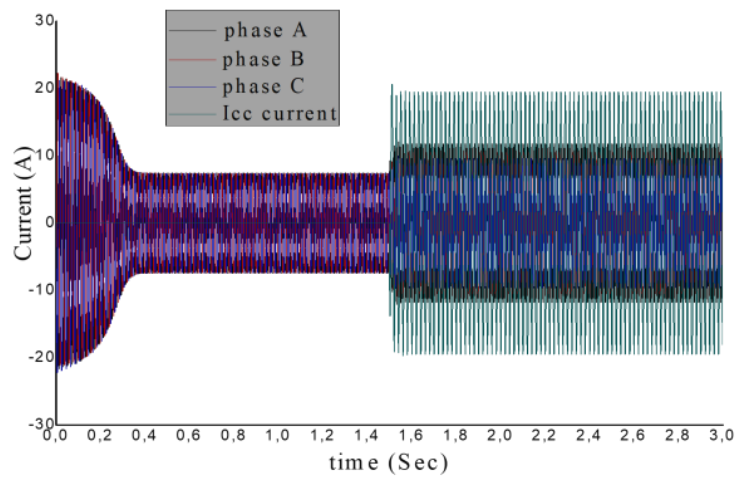

Figure 2. Stator currents resulting from $20 \%$ interturn short circuits with no fault and fault situation

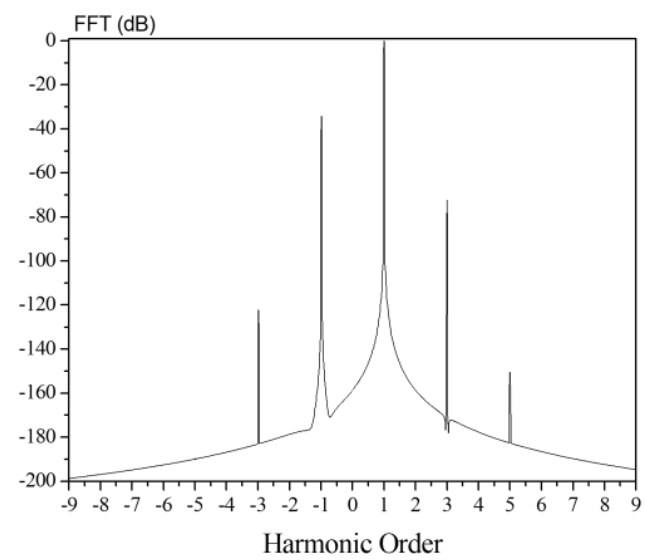

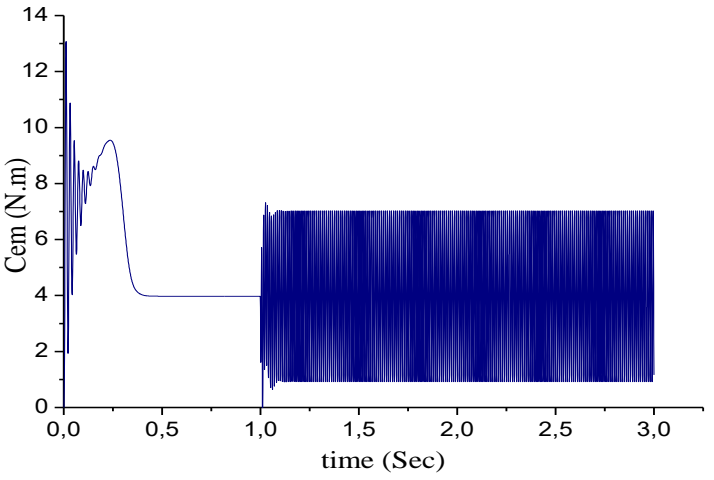

Figure 3. Detailed waveforms of motor torque from $20 \%$ of inter turn short circuits faults with no fault and fault situation

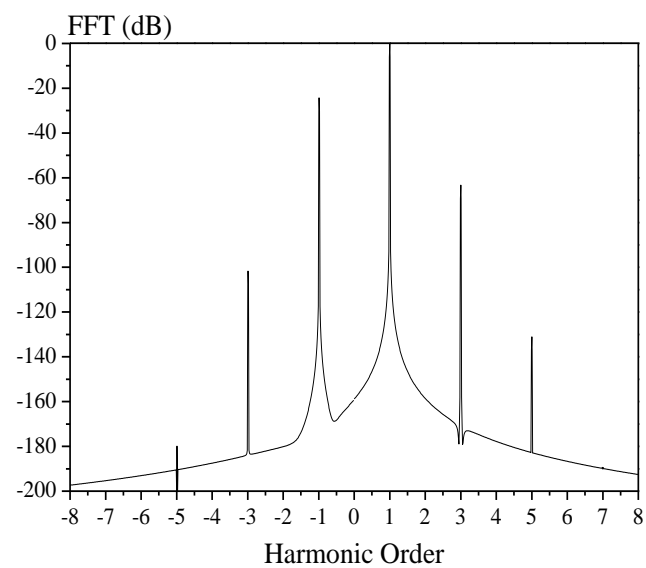

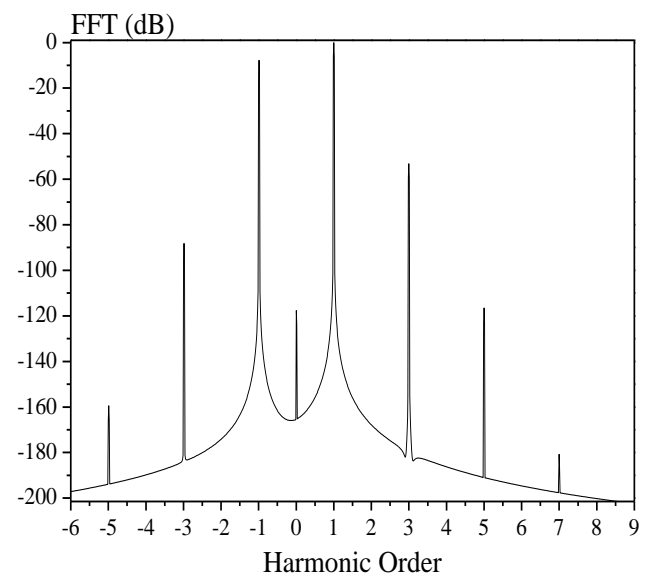

Figure 4. Simulation result of the spectra of the vector of park of an induction machine under $2 \%, 10 \%$ and $20 \%$ of inter-turn short circuit fault

\section{EXPERIMENTAL RESULTS AND DISCUSSION}

The experimental test bench has been developed to study different conditions of operation of the electric machine in the healthy state or with shorted faults under different load conditions. The load is a magnetic powder brake, which makes it possible to apply the different load torques. The tested induction machine used in experimentation is a three-phase asynchronous motor, $50 \mathrm{~Hz}, 4$ poles, $1.1 \mathrm{~kW}$, rated at $400 \mathrm{~V}, 2.95 \mathrm{~A}$ and $1450 \mathrm{rpm}$. The machine has re-winding with intermediate wires were distributed over two of the three phases with the objective of choosing previously a number of shorted turns. The welded connections are taken back to a terminal plate [29]. Measurements of the stator currents and voltages of the machine are performed using the voltage and current sensors. Then these values are recorded by 
the LeCroy Wave Runner 6050 oscilloscope which includes 4 signal acquisition channels, offers 5 GS s on each ADC channel and $1 \mathrm{MB}$ of standard memory. The sampling frequency chosen for each data acquisition is $25 \mathrm{kHz}$, for a duration of $2 \mathrm{~s}$. After acquisition, MATLAB programs are used for frequency domain analysis. To confirm experimentally the exactitude of the model we present normalized FFT spectral of the stator current motor in healthy condition and with $2 \%$ interturn shorted faults: no load condition as shown in Figure 5. These figures clearly show the same simulation fault frequencies. In the case of healthy conditions we remark the presence of negative sequence component frequency.It is universally known, that an electrical or magnetic non rotational asymmetry of induction machine or an asymmetry in the supply voltages can be detected through stator current negative component.After application of $2 \%$ interturn shorted faults the magnitudes of some frequencies are increase with the application of the fault. The complete observation from theses frequencies faults are given in Figure 6 for 10 and 20 of interturn shorted fault respectively. In a general way we remark that magnitude of third negative and five positive frequencies are very influenced by the fault. The experiment results have a satisfactory conformity with the simulation one what confirms the validity of the developed model. Interturn shorted faults are detected by study the comparison of specific frequencies amplitudes with and without the fault. It is also possible to know the percentage of the fault according to the amplitude in decibel.
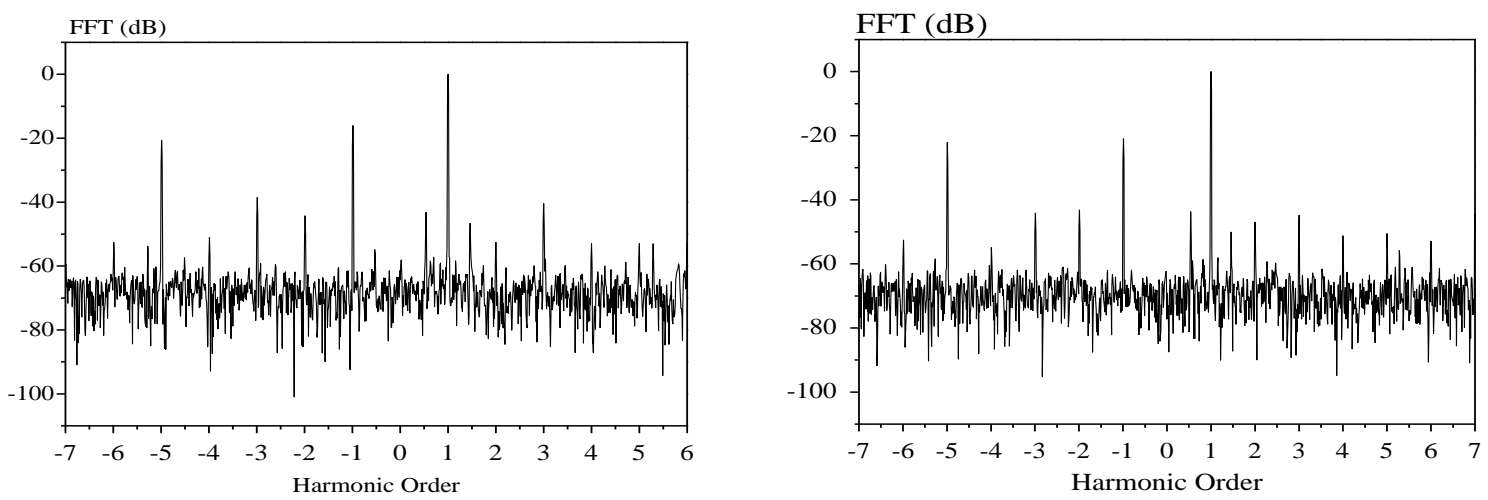

Figure 5. Normalized FFT spectrum of the stator current, machine in healthy machine (left), and $2 \%$ inter turn short circuits faults (right), no load condition
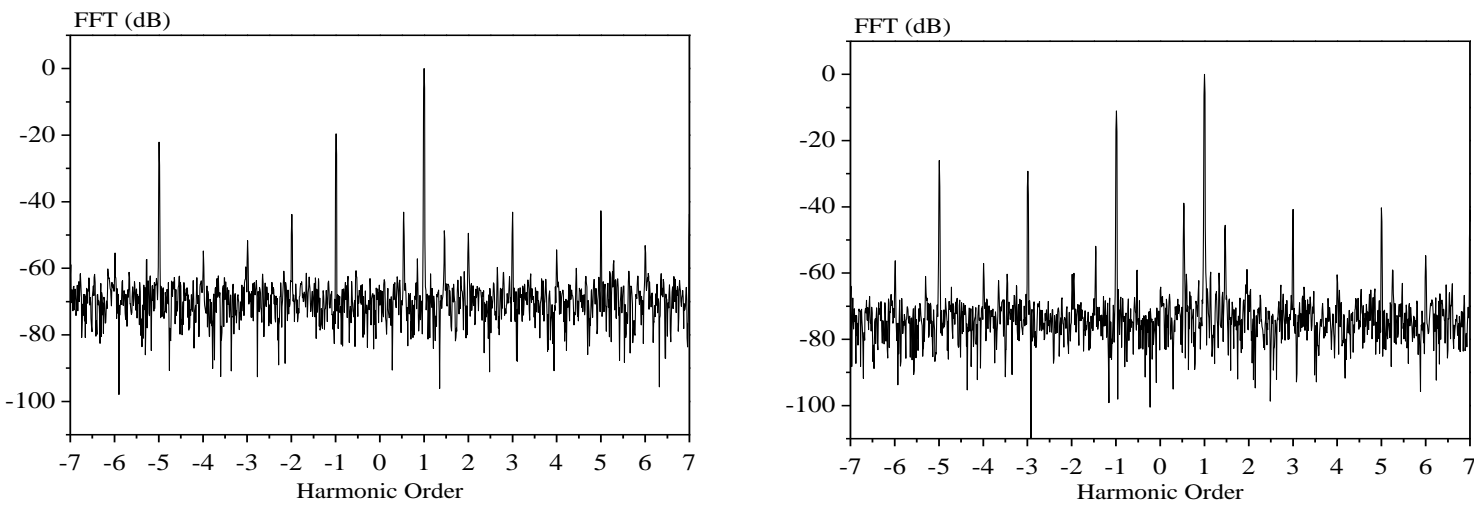

Figure 6. Normalized FFT spectrum of the stator current, machine with $10 \%$ (left) and $20 \%$ (right) of inter turn short circuits faults: no load condition

\section{CONCLUSION}

An accurate model for induction motors with turn to turn shorted faults is developed using reference frame transformation theory. Using motor current signature analysis method (MCSA) to diagnose and extract a good and accurate indicator related of the default, we confirm the effectiveness of the proposed model. The proposed model reduces the number of variable and cancelled the complexity of the rotor angular position. The originality of this paper is also to demonstrate the relationship between the interturn short circuit and unbalanced voltage supply. We remark in the model that the resemblance between interturn short circuit and unbalanced voltage supply is only reducing of amplitude of the voltage supply, and a same difference in its resistance. 


\section{REFERENCES}

[1] H. Henao, et al., "Trends in fault diagnosis for electrical machines: A review of diagnostic techniques," IEEE industrial electronics magazine, vol. 8, no. 2, pp. 31-42, 2014.

[2] K. M. Siddiqui, et.al., "Health monitoring and fault diagnosis in induction motor- a review," International. Journal of Advanced Research in Electrical, Electronics and Instrumentation Engineering, vol. 3, no. 1, pp. 6549-6565, 2014.

[3] L. Maraaba, Z. Al-Hamouz, and M. Abido, "An Efficient Stator Inter-Turn Fault Diagnosis Tool for Induction Motors," Energies, vol. 11, no. 3, 2018.

[4] H. Abdallah and K. Benatman, "Stator winding inter-turn short circuit detection in induction motors by parameter identification," IET Electric Power Applications, vol. 11, no. 2, pp. 272-288, 2017.

[5] Jagadanand G., et.al., "Inter-turn Fault Detection in Induction Motor using Stator Current Wavelet Decompsition," International Journal of Electrical Engineering \& Technology, vol. 3, no. 2, pp. 103-122, 2012.

[6] N. F. M. Yasid, et al., "The Effect of short circuitfault in three-phase core-typed transformer," International Journal of Power Electronics and Drive Systems (IJPEDS), vol. 11, no. 1, pp. 409-416, 2020.

[7] B. Akin, Liang Chen, Jiabin Wang, Zhigang Sun, "Electromagnetic-thermal coupled modelling and analysis of inter-turn short-circuit faults of a permanent magnet alternator," The Journal of Engineering, IET journal, The Institution of Engineering and Technology, vol. 2019, no. 17, pp. 4426 - 4431, Jun. 2019.

[8] M. h. Drif and A. J. M. Cardoso, "Stator fault diagnostics in squirrel cage three-phase induction motor drives using the instantaneous active and reactive power signature analyses," IEEE Transactions on Industrial Informatics, vol. 10, no. 2, pp. 1348-1360, 2014.

[9] L. Xiao, et al., "A New Diagnostic Method for Winding Short-Circuit Fault for SRM Based on Symmetrical Component Analysis," Chinese Journal of Electrical Engineering, vol. 4, no. 1, pp. 74-82, 2018.

[10] A. Garcia-Perez, et al., "The application of high-resolution spectral analysis for identifying multiple combined faults in induction motors," IEEE Transactions on Industrial Electronics, vol. 58, no. 5, pp. 2002-2010, 2011.

[11] A. A. Jaber, and R. Bicker, "Design of a Wireless Sensor Node for Vibration Monitoring of Industrial Machinery," International Journal of Electrical and Computer Engineering (IJECE), vol. 6, no. 2, pp. 639-653, 2016.

[12] A. Stavrou, H. G. Sedding and J. Penman, "Current monitoring for detecting inter-turn short circuits in induction motors," IEEE Transactions on Energy Conversion, vol. 16, no. 1, pp. 32-37, 2001

[13] M. S. Ballal, et.al, "Stator Winding Inter-turn Insulation Fault Detection in Induction Motors by Symmetrical Components Method," Electric Power Components and Systems, vol. 36, no. 7, pp. 741-753, 2008

[14] Tallam, R. M, Habetler, T. G and Harley, R. G, "Stator winding turn-fault detection for closed-loop induction motor drives," 37th IAS Annual Meeting IEEE Industry Applications Conference., vol. 3, no. 13-18, pp, 1553-1557, 2002.

[15] K. M. Siddiqui, K. Sahay, and V. K. Giri, "Stator Inter-turn Fault Detection in Inverter Fed Induction Motor Drives," International Journal of Applied Power Engineering (IJAPE), vol. 6, no. 2, pp. 89-102, 2017.

[16] N. A. Yusoff, et al., "The direct power control of three-phase AC-DC converter under unbalance voltage condition," International Journal of Electrical and Computer Engineering (IJECE), vol. 9, no. 6, pp. 5107-5114, 2019.

[17] A. A. Alawady, et al., "Frequency response analysis technique for induction motor short circuit faults detection," International Journal of Power Electronics and Drive System (IJPEDS), vol. 11, no. 3, pp. 1653-1659, 2020.

[18] A. Bouzida, et al., "An Experimental Study on Stator and Rotor Defects of Squirrel cage Induction Machines," XIX International Conference on Electrical Machines - ICEM 2010, Rome, 2010.

[19] Hashmia Sh. Dakheel, Z. B. Abdulla, and H. J. Jawad, "Faults detection and diagnoses of permanent magnet synchronous motor based on neuro-fuzzy network," International Journal of Applied Power Engineering (IJAPE), vol. 8, no. 2, pp. 173-185, 2019.

[20] A. A. Vinaya, and D. Arifianto, "Multi-way array decomposition on acoustic source separation for fault diagnosis of a motor-pump system," International Journal of Electrical and Computer Engineering (IJECE), vol. 7, no. 6, pp. 3052-3059, 2017.

[21] S. M. A. Cruz and A. J. Marques Cardoso, "Modelling and simulation of stator winding faults in three-phase induction motors, including rotor skin effect," 15th international Conference on electrical Machines, 2002.

[22] A. Gandhi, T. Corrigan, and L. Parsa, "Recent advances in modeling and online detection of stator interturn faults in electrical motors," IEEE Trans. Ind. Electron., vol. 58, no. 5, pp. 1564-1575, 2011.

[23] Andrzej Radecki, "Stator winding inter-turn short-circuit modelling of a squirrel-cage induction motor," Power Electronics and Drives, vol. 1, no. 1, pp. 139-148, 2016.

[24] Devanneaux V., Dagues B., Faucher J., Barakat G., "An accurate model of squirrel cage induction machines under stator faults," Mathematics and Computers in Simulation, vol. 63, pp. 377-391, 2003.

[25] A. Berzoy, et al., "Complex-Vector Model of Interturn Failure in Induction Machines for Fault Detection and Identification," IEEE Transactions on Industry Applications, vol. 53, pp. 2667-2678, 2017.

[26] M. Jannati, et al., "Modeling of balanced andunbalanced three-phase induction motor under balanced and unbalanced supply based on winding functionmethod," International Journal of Electrical and Computer Engineering, vol 5, no 4, pp. 644-655, 2015.

[27] R. M. Tallam, T. G. Habetler and R. G. Harley, "Transient model for induction machines with stator winding turn faults," IEEE Transactions on Industry Applications, vol. 38, no. 3, pp. 632-637, 2002.

[28] Xianrong Chang, V. Cocquempot and C. Christophe, "A model of asynchronous machines for stator fault detection and isolation," IEEE Transactions on Industrial Electronics, vol. 50, no. 3, pp. 578-584, 2003.

[29] F. Babaa, A. Khezzar and M. el K. Oumaamar, "Experimental investigation and comparative study of interturn short-circuits and unbalanced voltage supply in induction machines," Frontiers in Energy, vol. 7, no. 3, pp. 271-278, 2013. 